\title{
A study on the relationship between exercise addiction, abnormal eating attitudes, anxiety and depression among athletes in Israel
}

\author{
MAAYAN LEVIT ${ }^{1}$, AYELET WEINSTEIN $^{2}$, YITZHAK WEINSTEIN ${ }^{3}$, DANA TZUR-BITAN $^{1}$ and AVIV WEINSTEIN ${ }^{1 *}$ \\ ${ }^{1}$ Department of Behavioral Sciences and Integrative Brain and Cognition Center, Ariel University, Ariel, Israel \\ ${ }^{2}$ Department of Research and Sports Medicine, The Wingate Institute, Netanya, Israel \\ ${ }^{3}$ School of Nutritional Sciences, Tel Hai Academic College, Tel-Hai, Israel
}

(Received: August 30, 2017; revised manuscript received: January 12, 2018; second revised manuscript received: August 5, 2018; accepted: August 5, 2018)

\begin{abstract}
Background and aims: The aim of this study was to investigate the relationship between exercise addiction, abnormal eating attitudes, anxiety, and depression among competitive and amateur athletes. Methods: Participants were 100 athletes of mean age 28.3 years (18-62), of which there were 67 males and 35 females. The sample consisted of competitive and amateur athletes who participated in individual and group sports. They filled in the Exercise Addiction Inventory, Body Shape Questionnaire, a questionnaire assessing Eating Attitudes Test, Spielberger State-Trait Anxiety Inventory, and Beck Depression Inventory (BDI). Results: Ratings of exercise addiction were positively correlated with BDI scores across the study sample. Exercise addiction ratings were associated with abnormal eating attitudes, but not with trait or state anxiety. Athletes engaging in individual sports scored marginally higher on depression scores than group athletes but there was no difference in depression scores between competitive and amateur athletes. Multiple regression analysis revealed that abnormal eating attitudes contributed significantly to ratings of exercise addiction and explained $7.7 \%$ of the variance. According to the Sobel test, the difference in the association between exercise addiction and eating disorder was significant. Therefore, body shape was a mediating factor between eating disorder and exercise addiction. Discussion and conclusions: This study extends our preliminary findings of an association between exercise addiction and depression. Second, abnormal eating attitudes may explain most of the variance of exercise addiction. This is a further support for previous evidence of comorbidity between exercise addiction and eating disorders.
\end{abstract}

Keywords: exercise addiction, abnormal eating attitudes, depression, anxiety

\section{INTRODUCTION}

Studies on regular physical exercise over the past 20 years have shown that it has a positive effect on mood of individuals who exercise regularly (Craft \& Perna, 2004; Stanton \& Reaburn, 2014). In particular, supervised aerobic exercise, performed three times weekly at moderate intensity for a minimum of 9 weeks, was shown to be useful in the treatment of depression (Stanton \& Reaburn, 2014). Physical exercise may be a safe and effective addition to antidepressant therapy in late-life major depression (Murri et al., 2015). Although exercise is moderately effective for reducing symptoms of depression, when compared with psychological or pharmacological therapies, physical exercise does not appear to be more effective, although this conclusion is based on few small trials (Cooney et al., 2013).

Regular physical exercise has enhanced and improved the subjective assessment of quality of life and happiness (Huang \& Humphreys, 2012). It can also strengthen the motivation for achieving life's goals and taking control over one's personal life (Archer \& Garcia, 2014). Biological studies have shown that physical exercise can enhance serotonergic metabolism in mice (Greenwood et al., 2011). In humans, running long-term distance was associated with endorphin release and associated euphoria (Boecker et al., 2008).

Although it is well established that physical exercise is beneficial, excessive exercise can be harmful both physically and psychologically. It has been suggested that individuals with compulsive physical exercise experience powerful withdrawal symptoms (Szabo, 1995). Griffiths (2005) argued that compulsive physical exercise may have features of other addictions, such as salience, mood modification, tolerance, withdrawal symptoms, conflicts with peers and other activities, and relapse after periods of abstinence. There is supporting evidence that physical exercise can serve the mechanisms of reward, habituation, social support, and stress-relief (Berczik et al., 2012; Weinstein \& Weinstein, 2014). Exercise addiction may result in physical,

* Corresponding author: Aviv Weinstein; Department of Behavioral Sciences and Integrative Brain and Cognition Center, Ariel University, Ariel 40700, Israel; Phone: +972 3907 6555; Fax: +972 3906 6629; E-mails: avivwe@ariel.ac.il; avivweinstein@ yahoo.com

This is an open-access article distributed under the terms of the Creative Commons Attribution-NonCommercial 4.0 International License, which permits unrestricted use, distribution, and reproduction in any medium for non-commercial purposes, provided the original author and source are credited, a link to the CC License is provided, and changes - if any - are indicated. 
medical, financial, and social problems (Berczik et al., 2012). Finally, individuals who are addicted to exercise will continue exercising regardless of physical injury, personal inconvenience, or disruption to other areas of life including marital strain, interference with work, and lack of time for other activities (Landolfi, 2013).

In a previous study, Weinstein, Gavriel, and Weinstein (2015) have shown that ratings of compulsive physical exercise were positively associated with ratings of anxiety and depression among professional and recreational athletes. Second, professional athletes were more depressed than recreational athletes, but they did not show higher state or trait anxiety measures. Third, recreational athletes showed an association between compulsive exercise and depression ratings but not with ratings of state or trait anxiety. The authors have suggested that individuals who exercise regularly for recreational or professional purpose perform it for the means of alleviating the depression.

Exercise addiction also co-occurs with eating disorders (Freimuth, Moniz, \& Kim, 2011). There is evidence that those who are addicted to physical exercise show problematic eating patterns (Grandi, Clementi, Guidi, Benassi, \& Tossani, 2011). There is also an association between eating disorders and perception of body shape (Jones et al., 2001; Edman, Yates, Aruguete, \& DeBord, 2005). It is therefore plausible that the association between exercise addiction and eating disorders is mediated by perception of body shape.

This study aims at investigating the association between exercise addiction, depression, and eating disorders. Second, it aimed to examine the moderating effects of type of sports (group vs. individual) and reward (amateur vs. professional athletes) on these associations. First, it was hypothesized that exercise addiction would be associated with depression and anxiety ratings, particularly among those who practice individual sports. Second, it was hypothesized that exercise addiction would be associated with abnormal eating attitudes, but that this association would be mediated by perception of body shape.

\section{METHODS}

\section{Participants}

There were 100 participants who were divided into four groups: (a) 25 participants who exercise amateur individual sport, (b) 25 participants who exercise individual sport professionally, (c) 25 amateur participants who exercise group sport, and (d) 25 participants who exercise group sport professionally. All participants were between 18 and 62 years of age $(M=28.33, S D=8.38)$. The sample was recruited from an institute for physical education and sports through convenient sampling. The sample consisted of 65 males of mean age $28.77(S D=7.8)$ years and 44 females of mean age $27.49(S D=9.35)$ years.

\section{Measures}

Demographic Questionnaire includes details, such as age, sex, personal status, number of children, country of birth, place of living, education level, and employment status.
Beck Depression Inventory (BDI) is a self-reported inventory measuring characteristic attitudes and symptoms of depression (Beck, Ward, \& Mendelson, 1961). The inventory includes 21 items in which each item is rated on a scale from 0 to 4 . A total score is computed by summing the items. The BDI demonstrates high internal consistency, with Cronbach's internal reliability of $\alpha=.86$ and $\alpha=.81$ for psychiatric and non-psychiatric populations, respectively (Beck, Steer, \& Carbin, 1988). In this study, the BDI had a Cronbach's internal reliability of $\alpha=.85$. For the purpose of this study, depression was determined by an average score above 17 on BDI.

Spielberger State-Trait Anxiety Inventory (STAI) is a self-reported 40 items questionnaire; 20 items of Trait Anxiety Inventory and 20 items of State Anxiety Inventory (Spielberger, Gorsuch, Luschene, Vagg, \& Jacobs, 1983). Scores are measured on a Likert scale range from 1 "not at all" to 4 "agree very much." Total score is computed by summing the items whereby higher scores indicate greater trait or state anxiety. The STAI had been validated with an average Cronbach's internal reliability of $\alpha=.88$ (Spielberger et al., 1983). For the purpose of this study, general anxiety was calculated using the average score of Spielberger State Anxiety Inventory (SSAI) and STAI.

The Exercise Addiction Inventory (EAI) was validated by Griffiths, Szabo, and Terry (2005) that showed a Cronbach's $\alpha=.84$. The EAI was highly correlated $(r=.81)$ with the Exercise Dependence Scale (Downs, Hausenblas, \& Nigg, 2004; Hausenblas \& Downs, 2002) and with the Obligatory Exercise Questionnaire (Ackard, Brehm, \& Steffen, 2002; Pasman \& Thompson, 1988) $(r=.80)$ and it has a repeated test reliability of $r=.85$. For the purpose of this study, exercise addiction was determined using an average score of above 4 on the EAI (Griffiths et al., 2005).

The Eating Attitudes Test (EAT; Garner, Olmsted, Bohr, \& Garfinkel, 1982) measures behavioral and cognitive symptoms that are typical for eating disorders. Score above 20 indicates high prevalence of symptoms that relate to eating disorder and that can predict pathology (Mann et al., 1983). The questionnaire had high internal validity and reliability indices of eating disorders in the general population and in different cultures (Garner et al., 1982; Garfinkel \& Newman, 2001; Griffiths et al., 2015). In anorexic patients, the Cronbach's internal reliability measure was $\alpha=.7$ and in the control group it was $\alpha=.94$ (Solenberger, 2001). In this study, the Eating Attitude Questionnaire had a Cronbach's internal reliability of $\alpha=.87$. For the purpose of this study, the presence of eating disorder symptoms was determined by an average score of above 20 (Mann et al., 1983).

Body Shape Questionnaire (BSQ; Cooper, Taylor, Cooper, \& Fairbum, 1987) has 34 items on a point Likert scale that measures body shape (range: 34-204). It was validated with 573 young women (Cooper et al., 1987). In this study, Cronbach's internal reliability was $\alpha=.966$.

\section{Procedure}

All participants were recruited from the Wingate Institute for Physical Education and Sports in Israel. They have answered the following questionnaires by the Internet using Google docs. 


\section{Statistical and data analyses}

Data referring to gender differences in exercise addiction depression and anxiety measures were analyzed using a $\chi^{2}$ test. Comparisons between groups of athletes (professional vs. amateur athletes and individual vs. group athletes) were done using $t$-tests. Correlations between variables were done using Pearson's correlation tests. Multiple regression analysis was performed to investigate the effects of type of exercise, sex, depression and anxiety ratings, and abnormal eating attitudes on exercise addiction measures. In order to investigate body shape as a mediating variable, a Sobel test (Sobel, 1982) was performed. The analysis of the results was performed on Statistical Package for Social Science (SPSS, Windows v.20; IBM Corp., Armonk, NY, USA) using $p<.05$ threshold for statistical significance.

\section{Ethics}

The study was approved by the Institutional Review Board (IRB, Helsinki committee) of the University. All participants signed an informed consent form.

\section{RESULTS}

Descriptive analysis showed $12.1 \%$ of exercise addiction among men and $20 \%$ among women and an average of $14.9 \%$ in this sample. Four out of 65 males and 3 out of 35 females had high BDI scores, with mean BDI scores of $1.17(S D=0.14)$ for athletes engaging in group sports, 1.54 $(S D=0.53)$ for athletes engaging in individual sports, 1.45 $(S D=0.49)$ for athletes engaging in professional sports, and $1.43(S D=0.52)$ for athletes engaging in amateur sports. Eating disorder was evident among $9.1 \%$ of men and $28.6 \%$ of women. There was no sex difference in frequency of exercise addiction, $\chi^{2}(1)=1.123, p=.29$. There was no sex difference in frequency of depression, $\chi^{2}=0.224$, $p=.64$. Table 1 demonstrates questionnaire ratings in all participants.

The table shows that individual sports athletes scored higher than group sports athletes on the BSQ. In addition, individual sports athletes scored higher on the Eating Attitudes Scale compared with group sports athletes. Individual sports athletes had higher depression scores compared with group sports athletes. No significant differences were observed between the professional and amateur athletes.

The mean exercise hours per week among exerciseaddicted athletes was $8.47 \quad(S D=5.99)$ and 8.42 $(S D=8.22)$ in the non-exercise-addicted. The mean exercise hours per week for athletes exercising in competitive sports was $8.21 \quad(S D=5.43)$ and was $8.65(S D=9.98)$ among amateur athletes. The results indicated that there was a positive correlation between ratings of exercise addiction and depression in all participants $(r=.224$, $p<.05)$. There was a marginal difference in depression ratings between athletes with exercise addiction who performed individual sports compared with those who performed group sports, $t(1,12)=2.125, p=.054$. There was no difference in depression ratings between athletes with exercise addiction who were amateur sportsmen and those who were professional sportsmen, $t(1,13)=0.07$, $p=.95$. There was no correlation between exercise addiction and SSAI $(r=.66, p=.15)$ and STAI $(r=.59, p=.18)$.

A multiple regression analysis assessing the contribution of age, type of sport (individual vs. group), purpose (professional vs. amateur), general anxiety, depression, eating disorder, and body shape on the dependent variable of exercise addiction showed that only eating disorder contributed significantly to scores of exercise addiction $[F(1,99)=$ $\left.8.28, p<.05,\left(\beta=0.278, R^{2}=.077\right)\right]$ and it explained $7.7 \%$ of ratings of exercise addiction.

In order to test the second hypothesis that perception of body shape would be a mediating variable between abnormal eating attitudes and exercise addiction, we have performed a hierarchical linear regression with ratings of eating disorder and perception of body shape as independent variables and ratings of exercise addiction as a dependent variable. The regression analysis showed that eating disorder contributed significantly to ratings of exercise addiction $(\beta=0.278, p<.05)$ and that perception of body shape contributed significantly to ratings of exercise addiction $(\beta=0.216, p<.05)$. A second linear regression was performed with perception of body shape ratings as an independent variable and eating disorder ratings as dependent variable. Body shape ratings significantly contributed to ratings of eating disorder $(\beta=0.77, p<.01)$. After entering body shape as a mediating variable between eating disorder and exercise addiction, the contribution of exercise addiction to eating disorder became non-significant $(\beta=0.112$,

Table 1. Means and SDs of type of sports (group vs. individual) and type of sportsman (professional vs. amateur)

\begin{tabular}{|c|c|c|c|c|c|c|c|c|c|c|}
\hline & \multicolumn{2}{|c|}{ Group } & \multicolumn{2}{|c|}{ Individual } & \multirow[b]{2}{*}{$t$} & \multicolumn{2}{|c|}{ Professional } & \multicolumn{2}{|c|}{ Amateur } & \multirow[b]{2}{*}{$t$} \\
\hline & Mean & $S D$ & Mean & $S D$ & & Mean & $S D$ & Mean & $S D$ & \\
\hline EAI & 0.63 & 3.09 & 0.74 & 3.26 & -1.20 & 0.64 & 3.26 & 0.74 & 3.10 & 1.12 \\
\hline BSQ & 0.58 & 1.43 & 0.90 & 1.87 & $-2.82 * *$ & 0.72 & 1.57 & 0.85 & 1.75 & -1.09 \\
\hline EAT & 1.97 & 0.60 & 2.47 & 0.80 & $-3.55^{* *}$ & 0.75 & 2.23 & 0.76 & 2.24 & -0.09 \\
\hline STAI & 63.72 & 14.82 & 71.43 & 23.77 & -1.93 & 17.14 & 64.06 & 22.56 & 71.41 & -1.84 \\
\hline BDI & 24.68 & 4.09 & 27.39 & 7.36 & $-2.25^{*}$ & 5.81 & 25.76 & 6.52 & 26.45 & -0.56 \\
\hline
\end{tabular}

Note. SD: standard deviation; BDI: Beck Depression Inventory; STAI: State-Trait Anxiety Inventory; EAI: Exercise Addiction Inventory; EAT: Eating Attitudes Test; BSQ: Body Shape Questionnaire.

$* p<.05 . * * p<.01$ 
$p=.07)$. According to the Sobel test, the difference in the association between exercise addiction and eating disorder was significant $(Z=2.16, p<.05)$. Therefore, body shape is a mediating factor with strength of mediation of 0.116 .

\section{DISCUSSION}

This study has investigated the association between exercise addiction, depression, anxiety, and eating disorders. We have replicated a previous finding by Weinstein et al. (2015) of an association between exercise addiction and depression. It is already established that physical exercise can enhance positive affect (Stanton \& Reaburn, 2014). It is therefore difficult to explain how an initially pleasurable activity can be associated with depression. One possible explanation is that the exercise-addicted individual may feel a lack of control over physical exercise and that they suffer from withdrawal symptoms when they are unable to exercise (Weinstein et al., 2015). Furthermore, exercise-addicted individuals have to increase or enhance their exercise activity in order to obtain euphoria or feeling of "high" and that may result in conflict with family life, work, and social life (Freimuth et al., 2011). The intensity of physical exercise may also result in feelings of loneliness, lack of new social experiences, and enjoyment from a non-physical activity all of which may lead to depression.

The majority of studies investigating the prevalence rate of depression among athletes have been conducted with college athletes. The prevalence rate of depression among college athletes ranges from as low as $15.6 \%$ to as high as 21\% (Proctor \& Boan-Lenzo, 2010; Yang et al., 2007). However, there has been a general lack of consistency in the findings (Wolanin, Gross, \& Hong, 2015). It is well established that symptoms of exercise dependence are positively associated with mood deterioration and the length of involvement in physical activity (Adams, 2009; Berczik et al., 2012). Mood states can play a role in either the development or maintenance of exercise dependence (Costa, Hausenblas, Oliva, Cuzzocrea, \& Larcan, 2013). Individuals who are addicted to physical exercise are more depressed, anxious, tense, confused, and angry after missing a workout (Adams, 2009; Berczik et al., 2012; Hamer \& Karageorghis, 2007). Negative mood states and intensive exercise can be factors that can increase exercise dependence (Berczik et al., 2012; Costa et al., 2013; Hamer \& Karageorghis, 2007). The finding of an association between exercise addiction and depression has clinical and practical implications for athletes who may need to be screened and monitored for their mood. Although there is evidence that physical exercise can reduce depressive symptoms (Babyak et al., 2000; Da Silva et al., 2012; Mutrie, 1988; Mutrie \& Choi, 2000), the negative effects of compulsive physical exercise need to be investigated as well.

This study failed to find an association between exercise addiction and trait anxiety unlike the result reported by Weinstein et al. (2015). This may be due to the lack of a sufficient sample. We have also found only a marginal difference in depression between exercise-addicted individuals who practice individual compared with group sports. It was assumed that group sports may have social benefits and that it may reduce loneliness and depressive symptoms among exercise-addicted individuals. It is plausible that due to a small number of exercise-addicted individuals in this study, the effect of type of sport was not significant. Second, we have not found any differences in depression between amateur and professional exerciseaddicted individuals possible due to the variability of the different sportive activity in our sample.

The association between exercise addiction and eating disorders has been established earlier (Grandi et al., 2011; Freimuth et al., 2011; Müller, Loeber, Söchtig, te Wildt, \& de Zwaan, 2015). Exercise addiction is often secondary to eating disorder when individuals try to lose weight using medication, vomiting, or self-starvation ("athletic anorexia"). It can be the primary addiction when individuals try to improve performance and exercise to lose weight without having an eating disorder (Freimuth et al., 2011). Lichtenstein, Christiansen, Elklit, Bilenberg, and Støving (2014) have found that exercise-addicted individuals scored higher on eating disorder symptoms compared with nonaddicted individuals but not as high as eating disorder populations. They have argued that although exercise addiction is separate to an eating disorder, it shares some of the concerns of body and performance.

The results of this study confirm a moderate association between exercise addiction and abnormal attitudes toward eating. This finding has clinical implications since the occurrence of both eating disorder and exercise addiction often results in focusing on the eating disorder, as the main problem and exercise addiction remain untreated. The individual does not gain weight due to enhanced physical exercise (Freimuth et al., 2011). We therefore argue that in the case of comorbid eating disorder and exercise addiction, both disorders should be treated simultaneously. Otherwise, the addicted individual will continue to suffer from symptoms of exercise addiction and he/she will not gain weight due to excessive exercise and this will result in a persistent impairment in daily function.

In this study, it was found that the mediating variable of body shape was necessary to establish the association between abnormal eating attitudes and exercise addiction. The association between body shape and eating disorders has already been established (Edman et al., 2005; Jones et al., 2001). This finding points out to the complexity of this association and may have clinical implications for both exercise addiction and eating disorders. The attitudes and feelings about body shape lie in the core of body image. Changing the subjective evaluation of body shape may play an important role in treatment of both disorders.

We have found no sex differences in exercise addiction and depression in our sample. These negative findings are compatible with the literature that indicates that there is no sex difference in negative addiction exercise symptoms (Furst \& Germone, 1993). Modoio et al. (2011) confirmed that there have been no differences in the development of negative addiction exercise symptoms in males and females and that there have been no changes in the quality of life and mood of these athletes. However, ratings of depression were higher in females compared with males in their study. Interestingly, we have found no difference in the number of hours spent on physical exercise between addicted and 
non-addicted individuals, suggesting that this variable is not indicative of addiction.

\section{LIMITATIONS}

This study attempted to compare different types of physical exercise such as amateur versus professional sports and individual versus group sports. Due to a small number of addicted individuals in each cohort, the differences were marginal and non-significant. A larger sample that would be limited to a particular sport may improve the possibility of detecting differences between the various sports. Although the variable of body shape has been established as playing an important role in both eating disorders and physical exercise, further studies need to establish and validate this connection.

\section{CONCLUSIONS}

This study has established the association between exercise addiction, depression, and eating disorders. The results may have clinical implications for the treatment of these disorders. If untreated, exercise addiction may remain detrimental to those who want to feel happy but end up lonely and miserable.

Funding sources: The study was conducted as part of an academic course in behavioral addiction at the Ariel University, Ariel, Israel.

Authors' contribution: All individuals included as authors of the paper have contributed substantially to the scientific process leading up to the writing of the paper. The authors have contributed to the conception and design of the project, performance of the experiments, analysis and interpretation of the results, and preparation of the manuscript for publication.

Conflict of interest: The authors have no interests or activities that might be seen as influencing the research (e.g., financial interests in a test or procedure and funding by pharmaceutical companies for research). All authors report no conflict of interests regarding this study.

\section{REFERENCES}

Ackard, D. M., Brehm, B. J., \& Steffen, J. J. (2002). Exercise and eating disorders in college-aged women: Profiling excessive exercisers. Eating Disorders, 10(1), 31-47. doi:10.1080/ 106402602753573540

Adams, J. (2009). Understanding exercise dependence. Journal of Contemporary Psychotherapy, 39(4), 231-240. doi:10.1007/ s10879-009-9117-5

Archer, T., \& Garcia, D. (2014). Physical exercise influences academic performance and well-being in children and adolescents. International Journal of School and Cognitive Psychology, 1(1), e102. doi:10.4172/2469-9837.1000e102

Babyak, M., Blumenthal, J. A., Herman, S., Khatri, P., Doraiswamy, M., Moore, K., \& Krishnan, K. R. (2000). Exercise treatment for major depression: Maintenance of therapeutic benefit at 10 months. Psychosomatic Medicine, 62(5), 633-638. doi:10. 1097/00006842-200009000-00006

Beck, A. T., Steer, R. A., \& Carbin, M. G. (1988). Psychometric properties of the Beck Depression Inventory: Twenty-five years of evaluation. Clinical Psychology Review, 8(1), 77-100. doi:10.1016/0272-7358(88)90050-5

Beck, A. T., Ward, C., \& Mendelson, M. (1961). Beck Depression Inventory (BDI). Archives of General Psychiatry, 4(6), 561-571.

Berczik, K., Szabó, A., Griffiths, M. D., Kurimay, T., Kun, B., Urbán, R., \& Demetrovics, Z. (2012). Exercise addiction: Symptoms, diagnosis, epidemiology, and etiology. Substance Use \& Misuse, 47(4), 403-417. doi:10.3109/10826084.2011. 639120

Boecker, H., Sprenger, T., Spilker, M. E., Henriksen, G., Koppenhoefer, M., Wagner, K. J., \& Tolle, T. R. (2008). The runner's high: Opioidergic mechanisms in the human brain. Cerebral Cortex, 18(11), 2523-2531. doi:10.1093/cercor/bhn013

Cooney, G. M., Dwan, K., Greig, C. A., Lawlor, D. A., Rimer, J., Waugh, F. R., \& Mead, G. E. (2013). Exercise for depression. The Cochrane Library.

Cooper, P. J., Taylor, M. J., Cooper, Z., \& Fairbum, C. G. (1987). The development and validation of the Body Shape Questionnaire. International Journal of Eating Disorders, 6(4), 485-494. doi:10.1002/1098-108X(198707)6:4<485::AID-EA T2260060405>3.0.CO;2-O

Costa, S., Hausenblas, H. A., Oliva, P., Cuzzocrea, F., \& Larcan, R. (2013). The role of age, gender, mood states and exercise frequency on exercise dependence. Journal of Behavioral Addictions, 2(4), 216-223. doi:10.1556/JBA.2.2013.014

Craft, L. L., \& Perna, F. M. (2004). The benefits of exercise for the clinically depressed. Primary Care Companion to the Journal of Clinical Psychiatry, 6(3), 104-111. doi:10.4088/PCC. v06n0301

Da Silva, A. M., Singh-Manoux, A., Brunner, E. J., Kaffashian, S., Shipley, M. J., Kivimäki, M., \& Nabi, H. (2012). Bidirectional association between physical activity and symptoms of anxiety and depression: The Whitehall II study. European Journal of Epidemiology, 27(7), 537-546. doi:10.1007/s10654-0129692-8

Downs, D. S., Hausenblas, H. A., \& Nigg, C. R. (2004). Factorial validity and psychometric examination of the Exercise Dependence Scale-Revised. Measurement in Physical Education and Exercise Science, 8(4), 183-201. doi:10.1207/ s15327841mpee0804_1

Edman, J. L., Yates, A., Aruguete, M. S., \& DeBord, K. A. (2005). Negative emotion and disordered eating among obese college students. Eating Behaviors, 6(4), 308-317. doi:10.1016/j. eatbeh.2005.05.004

Freimuth, M., Moniz, S., \& Kim, S. R. (2011). Clarifying exercise addiction: Differential diagnosis, co-occurring disorders, and phases of addiction. International Journal of Environmental Research and Public Health, 8(10), 4069-4081. doi:10.3390/ ijerph8104069

Furst, D. M., \& Germone, K. (1993). Negative addiction in male and female runners and exercisers. Perceptual and Motor Skills, 77(1), 192-194. doi:10.2466/pms.1993.77.1.192 
Garfinkel, P. E., \& Newman, A. (2001). The Eating Attitudes Test: Twenty-five years later. Eating and Weight Disorders-Studies on Anorexia, Bulimia and Obesity, 6(1), 1-21. doi:10.1007/ BF03339747

Garner, D. M., Olmsted, M. P., Bohr, Y., \& Garfinkel, P. E. (1982). The Eating Attitudes Test: Psychometric features and clinical correlates. Psychological Medicine, 12(4), 871-878. doi:10. 1017/S0033291700049163

Grandi, S., Clementi, C., Guidi, J., Benassi, M., \& Tossani, E. (2011). Personality characteristics and psychological distress associated with primary exercise dependence: An exploratory study. Psychiatry Research, 189(2), 270-275. doi:10.1016/j. psychres.2011.02.025

Greenwood, B. N., Foley, T. E., Le, T. V., Strong, P. V., Loughridge, A. B., Day, H. E., \& Fleshner, M. (2011). Long-term voluntary wheel running is rewarding and produces plasticity in the mesolimbic reward pathway. Behavioural Brain Research, 217(2), 354-362. doi:10.1016/j.bbr.2010.11.005

Griffiths, M. D. (2005). A 'components' model of addiction within a biopsychosocial framework. Journal of Substance Use, 10(4), 191-197. doi:10.1080/14659890500114359

Griffiths, M. D., Szabo, A., \& Terry, A. (2005). The Exercise Addiction Inventory: A quick and easy screening tool for health practitioners. British Journal of Sports Medicine, 39(6), e30. doi:10.1136/bjsm.2004.017020

Griffiths, M. D., Urbán, R., Demetrovics, Z., Lichtenstein, M. B., de la Vega, R., Kun, B., \& Szabo, A. (2015). A cross-cultural re-evaluation of the Exercise Addiction Inventory (EAI) in five countries. Sports Medicine-Open, 1(1), 5. doi:10.1186/s40798014-0005-5

Hamer, M., \& Karageorghis, C. I. (2007). Psychobiological mechanisms of exercise dependence. Sports Medicine, 37(6), 477-484. doi:10.2165/00007256-200737060-00002

Hausenblas, H. A., \& Downs, D. S. (2002). How much is too much? The development and validation of the Exercise Dependence Scale. Psychology \& Health, 17(4), 387-404. doi:10.1080/0887044022000004894

Huang, H., \& Humphreys, B. R. (2012). Sports participation and happiness: Evidence from US microdata. Journal of Economic Psychology, 33(4), 776-793. doi:10.1016/j.joep.2012.02.007

Jones, J. M., Bennett, S., Olmsted, M. P., Lawson, M. L., \& Rodin, G. (2001). Disordered eating attitudes and behaviours in teenaged girls: A school-based study. Canadian Medical Association Journal, 165(5), 547-552.

Landolfi, E. (2013). Exercise addiction. Sports Medicine, 43(2), 111-119. doi:10.1007/s40279-012-0013-x

Lichtenstein, M. B., Christiansen, E., Elklit, A., Bilenberg, N., \& Støving, R. K. (2014). Exercise addiction: A study of eating disorder symptoms, quality of life, personality traits and attachment styles. Psychiatry Research, 215(2), 410-416. doi:10.1016/j.psychres.2013.11.010

Mann, A. H., Wakeling, A., Wood, K., Monck, E., Dobbs, R., \& Szmukler, G. (1983). Screening for abnormal eating attitudes and psychiatric morbidity in an unselected population of 15-year-old schoolgirls. Psychological Medicine, 13(3), 573-580. doi:10.1017/S0033291700047991

Modoio, V. B., Antunes, H. K. M., Gimenez, P. R. B. D., Santiago, M. L. D. M., Tufik, S., \& Mello, M. T. D. (2011). Negative addiction to exercise: Are there differences between genders? Clinics, 66(2), 255-260. doi:10.1590/S1807-59322011000200013
Müller, A., Loeber, S., Söchtig, J., te Wildt, B., \& de Zwaan, M. (2015). Risk for exercise dependence, eating disorder pathology, alcohol use disorder and addictive behaviors among clients of fitness centers. Journal of Behavioral Addictions, 4(4), 273-280. doi:10.1556/2006.4.2015.044

Murri, M. B., Amore, M., Menchetti, M., Toni, G., Neviani, F., Cerri, M., Rocchi, M. B., Zocchi, D., Bagnoli, L., Tam, E., Buffa, A., Ferrara, S., Neri, M., Alexopoulos, G. S., \& Zanetidou, S. (2015). Physical exercise for late-life major depression. The British Journal of Psychiatry, 207(3), 235-242. doi:10.1192/bjp.bp.114.150516

Mutrie, N. (1988). Exercise as a treatment for moderate depression in the UK National Health Service (abstract). Proceedings of Sport, Health, Psychology and Exercise Symposium (pp. 96105). London: Sports Council and Health Education Authority.

Mutrie, N., \& Choi, P. Y. (2000). III. Is 'Fit'a Feminist Issue? Dilemmas for exercise psychology. Feminism \& Psychology, 10(4), 544-551. doi:10.1177/0959353500010004017

Pasman, L. N., \& Thompson, J. K. (1988). Body image and eating disturbance in obligatory runners, obligatory weightlifters, and sedentary individuals. International Journal of Eating Disorders, 7(6), 759-769. doi:10.1002/1098-108X(198811)7:6< 759::AID-EAT2260070605>3.0.CO;2-G

Proctor, S. L., \& Boan-Lenzo, C. (2010). Prevalence of depressive symptoms in male intercollegiate student-athletes and nonathletes. Journal of Clinical Sport Psychology, 4(3), 204-220. doi:10.1123/jesp.4.3.204

Sobel, M. E. (1982). Asymptotic intervals for indirect effects in structural equations models. In S. Leinhart (Ed.), Sociological methodology 1982 (pp. 290-312). San Francisco, CA: JosseyBass.

Solenberger, S. E. (2001). Exercise and eating disorders: A 3-year inpatient hospital record analysis. Eating Behaviors, 2(2), 151-168. doi:10.1016/S1471-0153(01)00026-5

Spielberger, C. D., Gorsuch, R. L., Lushene, R., Vagg, P. R., \& Jacobs, G. A. (1983). Manual for the State-Trait Anxiety Inventory. Palo Alto, CA: Consulting Psychologists Press.

Stanton, R., \& Reaburn, P. (2014). Exercise and the treatment of depression: A review of the exercise program variables. Journal of Science and Medicine in Sport, 17(2), 177-182. doi:10.1016/j.jsams.2013.03.010

Szabo, A. (1995). The impact of exercise deprivation on well-being of habitual exercisers. Australian Journal of Science and Medicine in Sport, 27, 68-75.

Weinstein, A., Gavriel, M., \& Weinstein, Y. (2015). A study on the relationship between compulsive exercise, depression and anxiety. Journal of Behavioral Addictions, 4(4), 315-318. doi:10.1556/2006.4.2015.034

Weinstein, A., \& Weinstein, Y. (2014). Exercise addictiondiagnosis, bio-psychological mechanisms and treatment issues. Current Pharmaceutical Design, 20(25), 4062-4069. doi:10. 2174/13816128113199990614

Wolanin, A., Gross, M., \& Hong, E. (2015). Depression in athletes: Prevalence and risk factors. Current Sports Medicine Reports, 14(1), 56-60. doi:10.1249/JSR.0000000000000123

Yang, J., Peek-Asa, C., Corlette, J. D., Cheng, G., Foster, D. T., \& Albright, J. (2007). Prevalence of and risk factors associated with symptoms of depression in competitive collegiate student athletes. Clinical Journal of Sport Medicine, 17(6), 481-487. doi:10.1097/JSM.0b013e31815aed6b 